\title{
Sensitivity analysis to explain the excitability in a pyramidal neuron with application to Alzheimer's disease
}

\author{
Jakub Nowacki ${ }^{*}$, Hinke M Osinga', Jon T Brown², Andrew D Randall², Krasimira Tsaneva-Atanasova ${ }^{1}$ \\ From Twentieth Annual Computational Neuroscience Meeting: CNS*2011 \\ Stockholm, Sweden. 23-28 July 2011
}

Intrinsic excitability is one of the pillars of neuronal behaviour . Combined experimental and modelling studies of neuronal excitability often provide an important insight into the brain functions. In this work we analyse a unified model that we derived for CA1/3 pyramidal neurons in Hodgkin-Huxley formalism [1]. We explore the variations of the model behaviour through parameter sensitivity analysis. Model validation against the experimental current clamp data shows that our model reproduces the behaviour of pyramidal cells very well. A characteristic feature of $\mathrm{CA} 1 / 3$ pyramidal cell response is a higher frequency of the first spike pairs. We define an excitability measure that quantifies parameter sensitivity in our model and takes into account this unique feature of the response.

The analysis shows that the outward currents have a considerable influence on both excitability and the number of action potentials. An increase of high-voltage activated inward currents often decreases excitability, whereas an increase of low-voltage activated inward
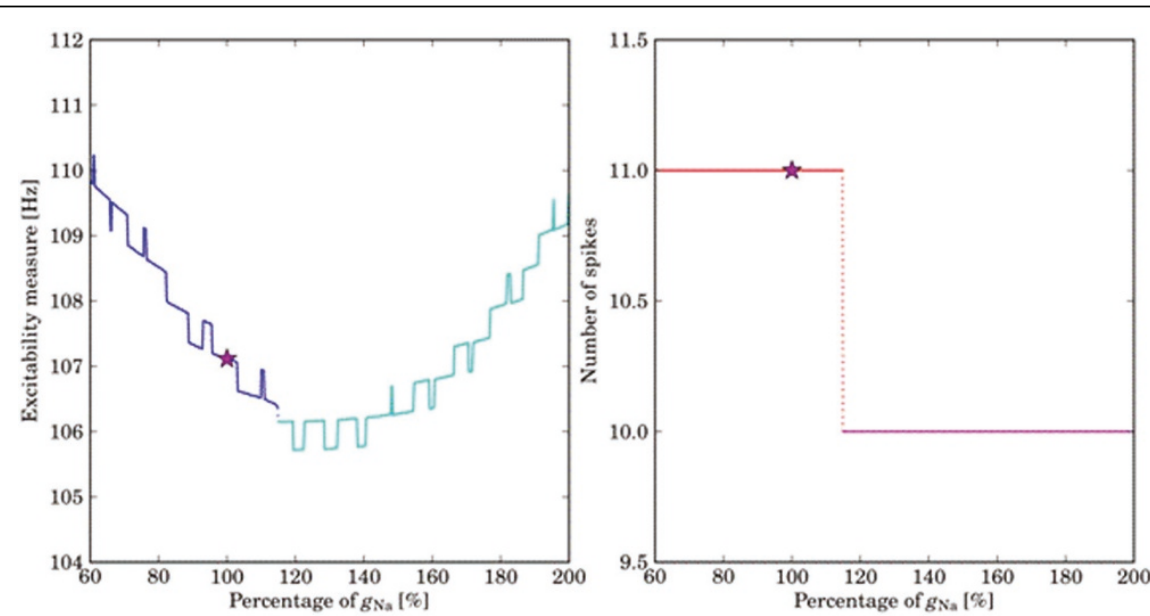

Figure 1 Sensitivity analysis of the maximal conductance of the combined Na+-currents; panel (a) shows the excitability measure ranging over the given percentages of the maximal conductance of Nat-currents; the original value of the maximal conductance is marked by a (magenta) star.

\footnotetext{
* Correspondence: j.nowacki@bristol.ac.uk

'Bristol Centre for Applied Nonlinear Mathematics, Department of Engineering Mathematics, University of Bristol, Queen's Building, University Walk, Bristol BS8 1TR, UK

Full list of author information is available at the end of the article
} 
currents results in a large increase of it. Moreover, the outward currents in our model have a profound impact on the number of action potentials. Counter-intuitively, we find that either a decrease or increase of total $\mathrm{Na}+$ current can result in an increase of excitability, as shown in Fig. 1

\section{Author details}

'Bristol Centre for Applied Nonlinear Mathematics, Department of Engineering Mathematics, University of Bristol, Queen's Building, University Walk, Bristol BS8 1TR, UK. ${ }^{2}$ Pfizer Applied Neurophysiology Group, MRC Centre for Synaptic Plasticity, School of Physiology and Pharmacology, University of Bristol, University Walk, Bristol BS8 1TD, UK.

Published: 18 July 2011

\section{Reference}

1. Nowacki J, Osinga HM, Brown JT, Randall AD, Tsaneva-Atanasova KT: A unified model of CA1/3 pyramidal cells: An investigation into excitability. Progress in biophysics and molecular biology 2010, Available http://www.ncbi.nlm.nih.gov/pubmed/20887748.

doi:10.1186/1471-2202-12-S1-P342

Cite this article as: Nowacki et al:: Sensitivity analysis to explain the excitability in a pyramidal neuron with application to Alzheimer's disease. BMC Neuroscience 2011 12(Suppl 1):P342.

\section{Submit your next manuscript to BioMed Central} and take full advantage of:

- Convenient online submission

- Thorough peer review

- No space constraints or color figure charges

- Immediate publication on acceptance

- Inclusion in PubMed, CAS, Scopus and Google Scholar

- Research which is freely available for redistribution

Submit your manuscript at www.biomedcentral.com/submit 